\title{
High-density thickening for large production rates: main challenges
}

\author{
S Barrera Delfi Ingenieria SpA, Chile \\ J Engels Tailpro Consulting, Chile
}

\begin{abstract}
It has been apparent for some time that for large production rates where high-density thickened tailings disposal is considered (e.g. Minera Centinela and Toromocho), significant challenges have been observed to reach the design underflow solids concentration. Many possible explanations have been proposed and at the 19th International Seminar on Paste and Thickened Tailings a panel discussion was held addressing this problem in detail. Usually the issue is a combination of operational parameters resulting in variable performance of an industrial thickener.

The purpose of this paper is to review and discuss the views raised in the panel discussion as indicated above, as well as visions/experiences on control and operational management of tailings thickeners for recent cases.
\end{abstract}

Keywords: thickening, thickener, operational control, panel discussion

\section{Introduction}

Tailings thickening technology has been present for more than 40 years. However, it is in the last 20 years that there has been a significant advance in the technology due to water use restrictions (need for further increase in recovery at the plant), environmental impact, and tailings disposal. In addition, tailings disposal with low water content has recently been recommended as best practice in the area of safety with the intent of reducing the environmental impact associated with catastrophic failure of retaining dams (which has been intensified by the Mount Polley and Fundão breaches). During the mid-1990s, a key advance in thickening technology was observed with the development and application of high-density tailings thickening technologies being applied.

High-density thickening technology commenced its development focusing on small operations of no more than 2,000 tpd of production and quickly grew, thanks to its positive results. There are several high-density thickening operations in the world with production generally under 20,000 tpd. In the mid-2000s, this technology started to be applied to much larger production tonnages, particularly in the area of copper mining, with Minera Centinela (formerly known as Minera Esperanza) and Toromocho having 100,000 and $117,000 \mathrm{tpd}$, respectively (design production rates). There is also the Sarcheshmeh project in Iran with a production of 96,000 tpd (MacNamara et al. 2011); however, there are important differences that have caused this operation to be excluded from this analysis. The first and most important is that the solids content of the thickeners discharge is $60 \%$, much lower than the target value of the other operations indicated above, and the second one is that no public information of the performance is available.

Minera Centinela started its operations in 2010 and Toromocho in 2013. Both operations have experienced challenges in achieving their design parameters related to tailings thickening and tailings management, which led to a significant increase of the capital and operating costs for both projects. The mining industry had placed expectations on the implementation of high-density thickening technology for high-tonnage production and the preliminary results of Minera Centinela and Toromocho has prevented other projects from developing similar technology. In fact, in some projects, the validity of this technology began to be questioned completely, classifying high-density thickening as unproven or as technology under development. 
The areas of greater uncertainty of this technology are focused on: (i) continuity in thickening performance (i.e. reliable solids content in the discharge), (ii) transport and distribution of thickened tailings, and (iii) tailings beach slopes. In each of these areas, there have been differences between design parameters and real data obtained in the field. One of the main variations is focused around variations between the tailings tested during feasibility study and pre-operation level and the tailings effectively processed by the plant. There are also restrictions on the operation of equipment, operator training and limited knowledge in the estimation of the beach slope and deposition management.

Minera Centinela has contributed significantly to the development of high-density thickening and has made public part of their studies and actions performed to investigate and overcome design and operational challenges (Thiele \& Parraguez 2011; Gaete \& Bello 2013; Gaete 2014; Gaete et al. 2014). For Toromocho, the design thickening rate has not been achieved and to the authors' knowledge, the possible causes, analysis, and corrective measures have not been publicly disclosed.

The authors are aware that previous papers have addressed some aspects of this subject. This is the case of Paterson (2006) where he identifies the importance of implementing control systems in the thickening process. More recently, Schoenbrunn et al. (2009) presents aspects to be considered in flocculation and feedwell systems but does not go into depth regarding the control methods.

A panel discussion on 'Challenges in the Implementation of Thickened Tailings and Paste Technology in Large Production Rates' was conducted during the 19th International Seminar on Paste and Thickened Tailings. This panel consisted of professionals involved in the design, testing, and manufacture of equipment and technologies associated with high-density thickened tailings. This paper is complemented with the presentation of the recent experience in thickening with special emphasis on the control of the thickening process and transport of thickened tailings.

\section{Panel discussion comments}

As presented previously, the causes for not reaching high thickening rates consistently for large throughputs are focused around the following areas:

- Definition of the minimum acceptable level of thickening for the project (not just the required/maximum), and the implications to tailings management if these values are not accounted for in the design phase.

- Correct characterisation of the current and future tailings and its variability during the mine life.

- Representativeness of samples and control conditions during pilot and laboratory tests to determine design parameters associated with thickening, transport, and disposal of the tailings slurry.

- Design of the thickener in accordance with the characteristics of the tailings and the solids content considered at the discharge. For example, the thickener type, rake, drive system, torque availability, and control systems implemented as part of the design.

During the panel discussion, the following questions had to be addressed by the panellists with regard to the difficulties of high-density thickening for large-production operations:

- Is today's thickening technology suitable for treating variable types of tailings to achieve high solids densities?

- Are thickener control systems currently appropriate? Or, in other words, are the operators able to safely manage and control the thickening operation?

- Are the tailings transport systems able to adapt to significant variations in consistency/yield stress?

- Could it be that the thickened tailings management approach has not been addressed in a holistic manner? 
- What should be the main driver(s) in the design of a system of thickened tailings?

- Is it possible to achieve a reliable and consistent high thickening rate in the close future?

As expected, the responses to these questions had different emphases depending on the area of expertise of the panel member. Notwithstanding this, several marked coincidences were detected.

\subsection{Tailings characterisation}

The correct characterisation of the tailings is key towards ensuring a good thickener design. This characterisation not only includes a definition of the average particle size distribution, but also the variability of this distribution, as well as the specific gravity, the clay content and types, and the variability with time of these parameters.

To achieve the above, it is necessary to include an investigation/characterisation program of the mineral during the exploration phase and to generate suitably representative tailings. The study of the metallurgical process characterises the minerals according to geometallurgical units (UGM), zoning and lithology, but the parameters that may affect the tailings management are not always included in this characterisation. It is therefore important that the characterisation of the mineral/tailings should form part of a holistic vision of the mine's operation and management and should be considered as part of the definition of the technologies associated with the extraction, processing and disposal.

In the presentation by Gonzalo Caro (Caro et al. 2016), a case study was presented of a mining operation in part of the Northern District of Codelco where a complete mineral characterisation was performed with the intent that it be used during the entire investigation process through to final tailings disposal. This is an example of an integral vision that understands that tailings management must start with knowing the mineral at its origin and its impacts in other phases of the process, even when blended with other ores.

\section{$2.2 \quad$ Pilot tests}

It is often commented that tailings are consistent in their form for an operation but in fact they can change frequently during the operational life of a mine. This has an impact on the stability of high-density thickening operations. This is partly due to the fact that at high solids densities the yield stress is very sensitive to change and can experience a rapid increase when the properties of the tailings are varied. This change is also very dependent on small variations in particle size (and in particular to the clay content and type) for which tailings that are apparently similar can have significant differences in behaviour. This suggests that the experience or precedence of similar tailings is not always useful (or applicable) and, when we want to design for high degrees of thickening, the execution of laboratory and pilot tests should include a wide range of thickening values of interest for the project, the variability of expected tailings should be known, and the equipment and technologies applicable to the tailings studied are well understood and implemented.

Frequently, there is reluctance over performing pilot tests because of their cost or the availability of representative samples. However, the alternative to performing laboratory-scale tests presents limitations, and therefore the execution of pilot tests is recommended. Pilot tests provide maximum benefit when the samples are representative of the ore during the period of study and when the scale of the test is appropriate for the final production - that is, there is no need for excessive scale-up. Some pilot trials have been similar to that of small mining operations but provide operations with better experience and knowledge of their ore and tailings properties prior to high investment costs associated with the development of a large-scale mining operation.

One aspect that was highlighted by Marco Becerra (Caro et al. 2016) is the limitation that exists in the sharing of experience and knowledge. There has often been resistance or opposition of many large mining companies to divulging information related to the behaviour of their tailings being tested for others to gain experience. That there is apprehension with providing information that may lead to sensitive information being divulged and potentially be misused by third parties is understandable, particularly during the study/permit phase. 
Even when considering these difficulties, the industry as a whole needs to have a longer-term vision to include benefits to the mining industry resulting from the knowledge and experiences gained by other operations. The mining industry must understand that the sharing of experience enhances the possibility of safer and environmentally friendly solutions, which is a clear benefit to the industry as a whole.

\section{$2.3 \quad$ Thickening equipment}

The design of thickeners for the mining industry has been evolving based on the need to increase the solids content at the discharge and the production rate to be treated. This is primarily the reason for the drive systems increasing in power at the same time that the rakes have been reinforced and their structural profiles modified to achieve more efficient performance. During the discussion panel, Fred Schoenbrunn provided examples of the increase in torque available in thickener drive systems from $3 \mathrm{MN}-\mathrm{m}$ (millions of newton metres) before 1990, $8 \mathrm{MN}-\mathrm{m}$ in 2005, and presently $13 \mathrm{MN}-\mathrm{m}$. This provides an idea of the large increase in power of these units as a consequence of a combination of greater densities and larger production rates. More recently, tubular style rake trusses are being used which presents structural advantages and low hydraulic disturbance as well as reduced weight. Schoenbrunn indicates that at Minera Centinela, a low-profile truss was changed to a tubular design and that there has been a significant improvement noted in the operation as a result.

Another area is the slope of the base of the thickener where there have also been enhancements, increasing the slope up to $14^{\circ}$ and higher in the case of high-rate thickening. However, paste technology introduces a greater challenge for large production, since the bottom slope is usually around $30^{\circ}$, with which the total height of large thickeners (for large productions) becomes very significant and can often be very costly to develop. The alternative is to have multiple smaller units, but this also presents operational challenges, such as the equal distribution of the tailings and the quantity of control systems required and their management. This therefore implies that achieving a highly thickened paste at large production rates using limited thickener units does not seem feasible at this time. In fact, the cases presented in the panel discussion only include high-rate thickening operations (not paste) for large productions.

Schoenbrunn commented that the thickener manufacturers indicate that:

"There are very different loading conditions for thickeners in paste and high-density applications, offset loading and imbalanced loads are a big issue, and so it's difficult for engineering firms to know what to specify. System control and communication is (also) an issue. Ideally, when we're designing a thickener we know exactly what the customer wants and what the engineering firm is trying to design to, but it's very rare for us to really be involved, particularly as far as how are we going to consistently supply something that the pumping system will work with." (Caro et al. 2016)

In this declaration, the manufacturers state the need to have a thorough involvement in the project phase (design criteria, operation range, tailings variability, etc.) to be able to develop the most appropriate design. One can infer that this involvement implies that the technology is not sufficiently mature and that there are still areas that require special analysis.

The above casts doubts on the convenience of having conventional bid processes. This type of bid process includes technical specifications. However, the specifications are generally not able to contain all the information and considerations and, in addition, it is not easy to introduce incentives for the manufacturer to provide input given the competitive nature of the processes. This leads us to wonder if preparing bid documents in those cases where the technology is not mature is justified or has technical validity and which characteristics should the relationship with the manufacturer have in order to obtain the best possible results within the uncertainty that a development of this nature presents. 
Christian Kujawa has a different opinion to the aforementioned comment when saying that:

"... maybe we haven't gone to the full evolution when it comes to high-density or paste equipment. So, control is, of course, very important and as we get closer and closer to what's possible in terms of removing the water like in a paste thickener, the degree of control when we are at the edge (limit) needs to improve vastly. And what happens very often, we stick with underflow solids concentration. And the reason for that is because it's so easy to measure, but in reality, all our processes and the thickener in the pumping, the spigotting, the beach slope, they are all rheology driven, but we do not have a piece of equipment that measures rheology. It's something that needs to be developed. When we compare the mining industry with oil and gas, the one thing (where) we are behind is having the instrumentation that tells us how to control the processes. We don't have it yet. I believe yield stress reduction is a process not really well understood, but I'm not quite sure that it's been used sufficiently in operations and then something which we see quite often is the necessary uncoupling between the thickening and the pumping."

The above could be construed as an expression that the technology has not evolved or could not have evolved at the desired speed and that, therefore, part of the responsibility lies with the manufacturers and the engineers who have not been able to modify this process to suit large production levels.

\subsection{Instability in the operation of high-density thickening}

A topic that in the opinion of the authors is relevant is that of the intrinsic instability of the thickening process in its paste phase. This subject was not addressed in detail during the panel discussion. The increase in the yield stress in a thickened tailings is directly proportional to the solids content of the tailings slurry. However, above a certain level of thickening, the increase in the yield stress can be very rapid (sometimes exponential). This behaviour is a consequence of the fact that the material is quickly approaching a change in state: passing from the liquid phase to the solid phase.

The consequence of the above is that the increase in yield stress is associated with a change in the density and a demand of more energy to move the tailings slurry. The above has been addressed by the manufacturers of thickeners through the design of more resistant rakes and drivers with increased power. However, there does not seem to have been an appropriate response to facilitate the operational management, or perhaps this is not easy to implement efficiently. We are referring to the fact that the operator requires a control system that allows for the adjustments of operational parameters in order to achieve the thickening goals and at the same time not risk sanding the thickener, damaging its operational components or sending tailings to the overflow systems.

It is important to always consider the variability of the tailings and the instability of the thickening process. The operational personnel require enough technical elements to allow them to adjust the solids content (or yield stress) both in the thickener mud bed and particularly at the discharge. A semi-manual operation (such as that which exists at many operations today) is not appropriate for this type of process since it requires a very rapid response to maintain the stability of the operation. This situation has presented itself in other cases and one of the solutions has been to instrument the operation such that the response is automatic through an expert system. This requires the inclusion of a significant number of inputs and sensors connected to a server that is programmed to instantly adjust the operation variables, but can be overridden by the operator as needed.

\section{Experiences on control and operational management}

Presuming that a particular thickener has been correctly designed and sized in terms of flux rate and retention time required to obtain the objective underflow density for a range of ore variability, then one of the main challenges associated with the operation of high-density thickened tailings is to maintain a stable balance within the thickener. That is, that the inflow mass, tailings properties and flow rates are relatively constant. This is very rarely the case (particularly for high-tonnage operations), as a tailings thickener is usually the last receiver of a product associated with a mineral processing operation. It is therefore subject 
to variations in the mineral type being processed and fluctuations in the operational efficiency of the processing plant and all processes upstream of the thickener.

Maintaining a constant mass inflow rate is normally a challenge and therefore control systems are needed to identify changes required in the dilution, flocculant dosages and underflow pump rates to compensate for this variation without jeopardising the operation of the thickener. For example, if a single ball mill goes offline, the mass inflow rate to the thickener can be reduced for a period of time, which may be less than the minimum discharge rate, resulting in a slow reduction of the net storage capacity through reduction of the mud bed level with time. Recycle systems, normally included in a higher-density thickener design, can be used to prevent sanding of the thickener, but many operators prefer not to use this method to prevent issues with overflow clarity and the requirements to change operational continuity (value changes, pump changes and post-flushing requirements). The result is that the bed reduces and the underflow density drops, taking time to increase once the inflow tonnage stabilises and the bed level increases in the thickener.

Most thickeners are controlled through instrumentation connected to a logic control system with a human machine interface (HMI). Systems such as a distributed control system (DCS), supervisory control and data acquisition (SCADA) and programmable logic controller (PLC) are most common and provide the input for the analysis of instrumentation to determine manageable data presentation and acquisition for the control room operation. The operator uses this series of instrumentation and logic systems to supervise the operation of each thickener and intervene as and when required. At the same time, it is common that the same operator is monitoring/operating other areas of the process, such as the water processing ponds, flocculant preparation plant, concentrate thickeners, etc. and is in constant radio contact with each of these areas. It is therefore necessary that the operator in the control room has the reliable information at his/her fingertips necessary to adapt to change rapidly or reduce the burden of supervision.

As mentioned previously, an expert system is now being normalised for operators in the control room to assist with trying to maintain continuity in a tailings thickener. This expert system is normally implemented every 15-30 minutes but can be overridden by the operator who is more knowledgeable about current operational performance, sensor reliability and anticipation to changes to the upstream process. This expert system relies on the correct operation of the instrumentation installed to prevent potentially generating further complications in the operation of the thickener. Typical inputs to the expert system are rake torque and position, bed depth, discharge flow rates, feed flow rates and density, and dry tonnage processed. The logic formulae also use this data to calculate the correct flocculant dosing requirement that the expert system then uses to recommend changes to dosage, based on factors such as bed height and rake torque.

Another important consideration is the position of the sensors installed controlling the operation of a thickener. This is important, as it impacts on the general operation and reaction time for changes to the thickener, with the potential to even be presenting misleading data to the operator and expert system. For example, a sonar-based mud level sensor may be positioned closer to the external wall of a thickener to advise the operator of potential loss of fines to the overflow. However, for a thickener of a large diameter, the level of the bed may not be horizontal if the operator increases the underflow discharge, and the time for the mud level sensor to react may be prolonged as a cone of depression forms inside the thickener, thus reducing the solids concentration in the underflow (typically located at the centre of the thickener). However, for the operator and expert system, this phenomenon is not known based on the HMI and data acquisition. Also, if a false bed occurs or heavy fines occur in the supernatant water, the sonar sensor will report a higher mud bed than is actually present, further complicating the operation.

As another example, it can be common for a mine that has several thickeners installed to calculate the flocculant dosage from the tonnage scale sensor feeding the plant. This is to reduce the costs associated with installing nuclear gauges on the feeds to each thickener. This means the logic gate systems used to calculate the flocculant flow rate to the feedwell receive tonnage data from a sensor typically located 30-60 minutes upstream of the thickeners for calculating instantaneous flocculant dosage in the feedwells. The fluctuations in the plant such as a reduction in tonnage in the crusher/mills or surges in flow rates to the thickeners (such 
as when a flotation cell is dumped or wash water is discharged to the tailings system) are not taken into account, leading to an incorrect flocculant dosage.

The main concerns of an operator in the control room is to not sand a thickener, exceed torque limitations of the equipment that can lead to structural damage or overheat drive systems and pumps, as well as the correct preparation/dilution of flocculant. These, for an operator in the control room, are generally a priority over the continuity of the underflow discharge density, which for others, such as the tailings facility operators and mine management (environmental permissions and company policies) can generate complications. It is therefore necessary to establish a balance in the operational set points of a thickener whereby the vendor of the equipment does not set too stringent limitations at values that are too low, causing operator intervention, and that the processing plant tries to provide a more stable delivery of tailings to the thickeners.

An example of a set point determined by a vendor is the torque, whereby a limit of $30-50 \%$ of the torque installed generates an alarm for the operator in the control room to react in one of three ways - reduce the level of the bed (increase the underflow pumps), reduce flocculant dosage or increase the height of the rakes (if a lifting system is installed). This is an operational condition that must be managed, but the reason why these limitations exist is not known in detail by the operator; he/she is generally abiding by the set points given in an operational manual or what has been set in the logic system. As the mine owner, they may ask why they paid to have $10 \mathrm{MN}-\mathrm{m}$ of torque installed if they can only use $40 \%$ of the value. If the rake system is only capable of levels of torque less than the motor design, say $60 \%$, why then is there the need for such a high installed torque value? The vendor may say that at $40 \%$ the increase in torque becomes exponential so that the time to react reduces before the thickener eventually sands or damages the rake/drive system. These types of limitations may be set based on a reduced knowledge and behavioural understanding of high-density thickening technology, to be conservative and protect vendor/owner assets. They may be relaxed with time, thus generating improved continuity in the operation of a high-density thickener.

Operator training is also key to the correct operation of a tailings thickener in general. Operators previously employed at other mines cannot apply knowledge and techniques to other thickeners, which may cause conflicts in their operation. It is also important that the operator is aware of the consequences of his/her actions and the mitigation measures necessary for particular events that occur. Thickener vendor operation manuals generally present generic guidance that is not specific to events that can occur at a particular operation. Experience and communication between the processing plant and tailings operators is also essential to ensure stability with the goal of anticipating changes that may occur with the operation of the thickeners based on upstream variability.

\section{Conclusion}

The technology of high-density thickening for large productions rates has presented significant challenges that have generated doubts regarding its application for tailings management, which has led to a discussion at an international level.

Achieving a high level of thickening of tailings for large production rates in a sustained and reliable manner involves the integration of the following variables/aspects:

- Complete geometallurgy/rheological knowledge of the tailings throughout the operation. This implies the understanding, among others, of the geology and the process prior to the generation of tailings. Laboratory and pilot tests are very useful studies to provide scale-up to larger production rates and determine variations in lithology/alterations that may impact the design and operational phases.

- Alliance between designer, thickener manufacturer and operator. This is necessary to understand that the successful management of highly thickened tailings requires an alliance between each specialist area. This alliance is important as each area is part of the problem, but at the same time part of the solution. Considering this, each of the parties involved must make it clear to the others what they need and what they expect. Likewise, the relationship must be developed under a 
framework that favours the exchange and establishes the right incentives for the designer, thickener manufacturer and operator.

- A semi-manual operation is in general not appropriate for this type of process, since it requires a very rapid response to maintain the stability of the operation. One of the solutions has been to instrument a thickener such that the response is automatic through an expert system (requiring the inclusion of a significant number of sensors connected to a server programmed to instantly adjust the operation variables). However, the position and calibration of the sensors need to be reviewed frequently to ensure reliability.

- Operator training is also key to the correct operation of a tailings thickener in general. Operators previously from other operations cannot apply knowledge and operational techniques to other thickeners which may cause conflicts in operation. It is also important that the operator is aware of the consequences of his/her actions and the mitigation measures necessary for particular events that occur. Thickener vendor operation manuals usually present generic guidance which is not specific to events that can occur at a particular operation. Training should be customised to the operation of a particular thickener.

- Experience and communication between the processing plant and tailings operators is essential to ensure stability of the thickening process, particularly to anticipate changes that may occur upstream.

It is the opinion of the authors that the location of instrumentation and the inputs to logic systems associated with the control of a high-density thickener are located correctly, and that they measure reliable data. There have been advancements in the use of instrumentation in the last decade in the area of thickening that allow improved data collection to advise an operator of real-time performance. However, it is important that the instrumentation used is frequently checked and calibrated to ensure continuity and reliability of the operation, as well as confidence in the data being produced.

It is observed that many limitations and set points of high-density thickeners are relatively generic, such as torque, which are set to protect installed assets rather than on an understanding of the real set points for a particular operation and its tailings properties. In operational manuals reviewed over recent years from major high-density thickener vendors, it's not specifically stated why these set point values exist at the values presented and what the limitations are regarding the mechanical systems installed for a particular thickener. As mentioned previously in this paper, it is therefore necessary that the vendor is involved with the full knowledge of a particular project as part of the pilot studies to better understand and recommend limitations, as well as improve mechanical design aspects associated with a particular project's tailings.

\section{References}

Caro, G, Schoenbrunn, F, Becerra, M \& Kujawa, C 2016, Challenges in Implementation of Highly Thickened Tailings Technology in Large Production Rates, in S Barrera (ed.), 19th International Seminar on Paste and Thickened Tailings edited panel transcription, http://paste2016.com/images/panel/16PST\%20Discussion_panel_transcription\%2017.01.25.pdf

Gaete, S 2014, 'Applying large-scale thickened tailings technology on the sulfide line at Minera Centinela', in S Barrera (ed.), Proceedings of the 2nd International Seminar on Tailings Management, Gecamin, Santiago.

Gaete, S \& Bello, F 2013, 'Experience with the thickening and discharge of high-density tailings - Minera Esperanza', in S Barrera, M Niederhauser, G Shaw, D van Zyl and W Wilson (eds), Proceedings of the 1st International Seminar on Tailings Management, Gecamin, Santiago.

Gaete, S, Bello, F, Engels, J \& McPhail, GI 2014, 'Thickening and deposition trials: laboratory through to industrial scale - Minera Esperanza', in RJ Jewell, AB Fourie, PS Wells and D van Zyl (eds), Proceedings of the 17th International Seminar on Paste and Thickened Tailings, InfoMine Inc., Vancouver, pp. 381-392.

McNamara, L, Khoshniaz, N \& Hashemi, S 2011, 'The Sarcheshmeh thickened tailings disposal project', in RJ Jewell \& AB Fourie (eds.), Proceedings of the 14th International Seminar on Paste and Thickened Tailings, Australian Centre for Geomechanics, Perth, pp. 237-244.

Paterson, AJC 2006, 'Rheology control of paste and thickened tailings systems', in RJ Jewell, S Lawson and P Newman (eds), Proceedings of the Ninth International Seminar on Paste and Thickened Tailings, Australian Centre for Geomechanics, Perth, pp. 47-56.

Schoenbrunn, F, Niederhauser, M \& Baczek, F 2009, 'Paste thickening of tailings: Process and equipment design fundamentals relative to deposition goals', in M Deepak, PR Taylor, E Spiller and M LeVier (eds), Recent Advances in Mineral Processing Plant Design, Society for Mining, Metallurgy \& Exploration, Littleton, pp. 455-465.

Thiele, C \& Parraguez, L 2011, 'Presentación, Minera Esperanza', Seminario de Relaves en Pasta, presentation, viewed 5 February 2018, http://www.relpas.cl/neo_2011/pdf/2011/M1/02\%20Christian\%20Thiele\%20\&\%20Leonardo\%20Parraguez.pdf 